\title{
ORBITAL MENINGOCELE*
}

\author{
BY \\ B. N. CONSUL AND O. P. KULSHRESTHA \\ Department of Ophthalmology, Sawai Man Singh Medical College, Jaipur, India
}

ORBITAL meningoceles are very rare congenital abnormalities in which the meninges, with the enclosed spinal fluid, herniate into the orbit. The protrusion is usually through a defect in the bony walls of the orbit or, much less commonly, at the site of natural openings like the optic foramen and sphenoidal fissure.

In the embryonic development of the bony orbit gaps occur through which herniation of the meninges takes place. When only the meninges, with enclosed spinal fluid, make up the orbital tumour it is a meningocele; when part of the brain tissue is also prolapsed it is an orbital encephalocele; if the cerebral ventricle is included in the tumour it is a hydrencephalocele.

The anterior variety is much more common, occurring between the junction of the frontal and lacrimal bones, cribriform plate, and nasal process of the superior maxilla. The tumour protrudes from the inner angle either towards the lids or the root of the nose, it not infrequently resembles a distended lacrimal sac, and it is often multilocular in this situation.

The posterior type is less common, where herniation occurs either through the sphenoidal fissure, optic foramen, posterior ethmoidal foramen, or in the roof or medial wall of the orbit.

The majority of these cystic herniations contain some brain substance, although the latter may undergo extreme atrophy and degeneration owing to long-continued pressure, so that the pia-arachnoid may become hardly recognizable and the dura thin and fibrous.

In meningoceles abnormalities of the eyes are not common. The abnormalities encountered are microphthalmos, coloboma of the iris, hydrophthalmos, and apparent anophthalmos (Duke-Elder, 1952). Pahwa and Patney (1963) reported three cases of meningo-encephalocele with association of microcornea and enophthalmos in one of these. This condition constitutes one of the very rare causes of exophthalmos.

The clinical picture usually becomes evident at birth or in early infancy. The cysts are fluctuant to a variable degree and some can be reduced by direct pressure. Pulsation of such cysts is uncommon as the pedicle is usually small.

On radiographic examination bony defects opposite the cyst may be seen. In the absence of pulsation or bony defects aspiration of fluid, resembling cerebrospinal fluid, from the cystic tumour will confirm the diagnosis.

\footnotetext{
* Received for publication December 1, 1964.
} 


\section{Case Report}

A 1 $1 \frac{1}{2}$-month-old girl was admitted on October 31, 1961 with a gradually increasing swelling in the inner angle of the left orbit, which was overlying the lacrimal sac area and extending towards the medial side of both the upper and lower lids. The swelling was noticed a few days after birth and was gradually increasing in size and had caused oedema of the lids in the left eye.

Family history was of no significance. The child had a normal delivery. On examination there was a large cystic swelling lying in the lacrimal sac area and extending to the medial side of the left lower and upper lid. It was loculated and externally it seemed as if there were two swellings, but on deep palpation it was found to be one swelling. It was slightly reducible on pressure. A transillumination test was positive. There was a small capillary haemangioma on the medial angle of the right eye, but apart from this there was no other abnormality in either eye.

Radiographic examination was not very helpful as the child could not co-operate. A diagnostic aspiration was done and $1.5 \mathrm{ml}$. of clear watery fluid was removed, but the swelling soon filled up again. Chemical examination of the aspirated fluid showed it to resemble cerebrospinal fluid with protein $50 \mathrm{mg}$. per cent., sugar $60 \mathrm{mg}$. per cent., and chlorides $720 \mathrm{mg}$. per cent. Microscopic examination of the fluid showed no cells, except for a few degenerated polymorphs.

During the patient's stay in hospital the swelling increased in size (see Figure).

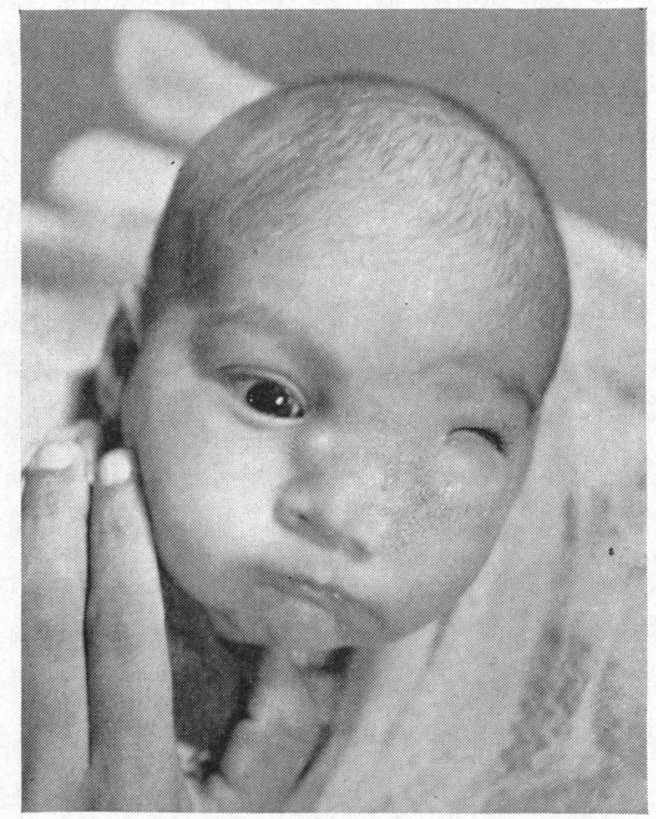

Photograph in a case of orbital meningocele before operation showing oedema of the lids. There is a small haemangioma on the opposite side.

Under general anaesthesia a vertical incision was made on the medial swelling. This incision was extended horizontally to include the lateral expansion of the swelling on the medial side of the lower lid. Both the lobules of the cystic swelling were connected far back posteriorly. The swelling had a very narrow pedicle and obviously was through a defect between the frontal and the lacrimal bones.

Catgut purse-string sutures (3-0) were applied to close the pedicle but these gave way. The pedicle was then transversely ligated and sutured. The conjunctiva and the wound were then closed.

On the third post-operative day the dressing was thoroughly wet from seepage of clear watery fluid (cerebrospinal fluid). On the fifth day two of the skin sutures gave way because of constant 
seepage of cerebrospinal fluid. On the sixth day all the skin sutures had given way as there was constant overflow of cerebrospinal fluid through the wound.

The child was given $50 \mathrm{mg}$. Achromycin 6-hourly by mouth to prevent infection. Secondary suturing was done, but the sutures again gave way because of the seepage of fluid. The wound was dressed with penicillin and streptomycin powder.

The wound started filling from the floor with red smooth granulation tissue, but seepage of cerebrospinal fluid persisted. Five weeks after operation this seepage had stopped and the wound closed well.

\section{Discussion}

This case has been reported because of the rarity of the condition and some interesting problems encountered on excising the meningocele surgically. It is interesting to note that there was a capillary haemangioma on the inner angle of the other eye.

Pahwa and Patney (1963) write that the treatment of this condition is unsatisfactory and carries a high mortality if excision is attempted. This cyst was excised and ligatured at the pedicle. There was leakage of cerebrospinal fluid post-operatively, but the area of the defect closed and filled up with granulation tissue.

When a cystic swelling appears in infancy or early childhood in the inner angle of the orbit, the possibility of orbital meningocele should be considered. Chemical examination of the aspirated fluid will confirm the diagnosis.

\section{Summary}

There is little in the literature about the rare condition of orbital meningocele, an anomaly which should be suspected when a cystic swelling appears at the inner angle of the orbit in infancy or early childhood. A female child, aged $1 \frac{1}{2}$ months, was successfully treated by excision of the meningocele, although post-operatively there was leakage of cerebrospinal fluid, which eventually subsided.

We are grateful to Dr. M. G. Sarin, neuro-surgeon, S.M.S. Hospital, Jaipur, for his valuable help, and to Dr. N. C. Desai, ophthalmologist, Victoria Hospital, Ajmer, for referring this case to us.

\section{REFERENCES}

DUKe-Elder, S. (1952). “Text-book of Ophthalmology”, vol. V, p. $4754 . \quad$ Kimpton, London. Pahwa, J. M., and Patney, H. L. (1963). J. All-India ophthal. Soc., 11, 100. 